\title{
$5-2012$
}

\section{Gender, Social Bond, and Academic Cheating in Japan}

\author{
Emiko Kobayashi \\ Kanazawa University \\ Miyuki Fukushima \\ Cleveland State University, m.fukushima@csuohio.edu
}

Follow this and additional works at: https://engagedscholarship.csuohio.edu/clsoc_crim_facpub

Part of the Criminology Commons, and the Educational Sociology Commons

How does access to this work benefit you? Let us know!

Publisher's Statement

(c)Alpha Kappa Delta (International Sociology Honor Society)

\section{Repository Citation}

Kobayashi, Emiko and Fukushima, Miyuki, "Gender, Social Bond, and Academic Cheating in Japan" (2012). Sociology \& Criminology Faculty Publications. 104.

https://engagedscholarship.csuohio.edu/clsoc_crim_facpub/104 


\title{
Gender, Social Bond, and Academic Cheating in Japan*
}

\author{
Emiko Kobayashi, Kanazawa University \\ Miyuki Fukushima, Cleveland State University
}

\begin{abstract}
There is evidence that females are less likely to cheat than males on college campuses. A frequently offered but still untested explanation is that females, with a stronger sense of responsibility for the maintenance of social relationships, tend to develop a stronger bond to a conventional society - a key explanatory concept in Hirschi's (1969) social control theory. With academic cheating as the dependent variable, we test the hypotheses that the four elements of social bond are the intervening variables linking gender to such dishonesty among Japanese students who, due to their stronger orientation toward masculinity on Hofstede's (1980) scale of gender role separation, are subject to more gender distinct socialization, leading to greater gender differences in the strength of social bond than those previously reported in the United States. The analysis provides rather limited support for the theory, most of which is due to the stronger belief in the legitimacy of societal rules among the females.
\end{abstract}

Unlike many other forms of deviance, gender is not consistently related to academic cheating in the United States (see Whitley, Nelson, and Jones 1999 for a review). This is in part because "the magnitude of the difference is greater for serious and violent offenses than for more common and trivial criminal acts" (Tittle and Paternoster 2000:316). Meanwhile, evidence shows that such academic dishonesty is more common among males than among females (Whitley, Nelson, and Jones 1999). Yet, little attention is given in sociological theories of deviance to this gender difference.

Ward and Beck (1990) noted decades ago that there is a clear and logical relationship between sex-role socialization and tendencies toward academic dishonesty. Whitley, Nelson, and Jones (1999) suggest, but offer no evidence, that female students, with the moral self-embedded within social relationships and encumbered by responsibilities for the maintenance of such relationships, tend to develop a stronger tie to conventional others, leading to their less inclination toward cheating. This untested hypothesis highlights a possibility that social control theory, presented by Hirschi (1969), might be a potential tool for understanding the relationship between gender and cheating. He contends 
that the strength of individuals' bonding to social institutions operates as effective informal social control over time, which in turn decreases the likelihood of deviant behaviors.

The female tendency to commit less academic cheating already has been documented. The present study is the first to provide direct evidence of the relationship among gender, social bond, and cheating among Japanese college students. Our hypothesis is that Japanese females, compared with males, report lower levels of such dishonesty because they score higher on all four elements of social bond identified in the theory-attachment, commitment, involvement, and belief. Thus, we propose an examination of one of the important issues identified by the feminist approach in the study of gender and deviance: the gender gap which concerns whether existing theories of deviance could explain why females commit less crime and other forms of deviance than males (Daly and Chesney-Lind 1988), testing these four elements as the intervening variables linking gender to cheating.

The present research focuses on academic cheating because it is a serious form of deviance and, reflecting Gottfredson and Hirschi's (1990:15) definition of crime, it is a fraudulent use of someone else's knowledge for an individual's gain. Furthermore, it is not merely a reflection of a momentary lapse of good judgment that young people grow out of as they enter adulthood; rather, it can become "a generalized behavioral pattern" which, in various forms of white-collar crimes, repeats in the labor market (Sims 1993). The research also examines academic cheating among Japanese college students because, unlike other forms of deviance, such dishonesty is found more prevalent in Japan than in the United States (Diekhoff et al. 1999). In addition, while cheating is often considered more gender-neutral deviance in American criminology (see Crown and Spiller 1998 for a review), researchers, especially Hofstede (1980), in the field of cross-cultural psychology find that Japan is oriented more toward "masculinity" in which gendered socialization is more distinct, leading to greater gender differences in the strength of bonding to a conventional society and then the commission of cheating among the Japanese.

\section{Gender and Academic Cheating}

Cheating among students is one of the major problems in education today (Singhal 1982), and it has been recognized as epidemic at all levels throughout the U.S. (Center for Academic Integrity 2006) and around the world (Grimes 2004). In the United States, for example, Vowell and Chen (2004) report that 88 percent of students commit some forms of cheating, while McCabe, Trevino, and Butterfield (2001) observe that the cheating rate has been increasing over the past 30 years. In Japan, Yoshida and Nakagawa (1971) find that 62 
percent of elementary, junior high, and high school students engage in cheating and 51 percent of college students commit acts of such dishonesty.

While universities and organizations such as the Educational Testing Service are taking steps to address such problems (MSNBC 2005), research on academic cheating typically concentrates on identifying demographic characteristics, personality traits, and situational factors that are related to such dishonesty (see Crown and Spiller 1998 for a review). Perhaps the first study to provide evidence of gender differences in college cheating is Bowers (1964). This work reveals that 43 percent of the female respondents admitted to cheating, while the corresponding figure for the males was 54. In Japan, Yoshida and Nakagawa (1971) report that 45 percent of females participated in some forms of cheating and the comparable percent for males was 53.

In a series of studies, Tibbetts $(1997,1999)$ reports similar findings. The author presented a vignette but realistic nature of scenario to college students; it included a description in which a character copies another student's answers during an examination. Respondents then rated the probability that they would do what the character did in the scenario, with response options ranging from 0 (no chance at all) to $10(100 \%)$. The author found that male students are more likely to cheat than females. The mean cheating intent was 3.50 for males and 2.39 for females in one study, whereas that was 4.18 for males and 3.50 for females in the other.

Questioning the validity of this hypothetical situation, Whitley (2001) conducted a study instructing college students to indicate how many examinations they had taken and cheated over the past 6 months. A cheating rate was then calculated by dividing the number of examinations on which the respondents had cheated by that which they had taken. In a whole sample of respondents, male students are more likely to report having cheated at least one examination. When the analysis was performed only for the respondents who admitted to cheating on an examination, however, the conclusions were different; among the subgroup of respondents, the gender difference in the cheating rate was not significant. On the contrary, the males have more favorable attitudes toward cheating and the cheating rate was positively correlated with favorable attitudes toward such behavior. These findings, Whitely speculates, are an indication that gender differences in cheating are a mirror, if not a parity, of those in attitudes toward the behavior.

This speculation is supported by Lin and Wen (2007) in their study of college students in Taiwan. Respondents were instructed to indicate their commission of cheating in college and acceptance of such behavior. Male students, compared with females, not only are more likely to cheat, but also are more agreeable to all four areas of cheating included in the study: cheating on tests, cheating on assignments, plagiarism, and others. Moreover, the correlation 
between attitudes and behavior was positive and significant for all these four areas.

Despite the evidence of lower levels of cheating among females, explanations for why these differences exist are rare and untested. This is not surprising, however, because most criminological theories were based on male samples to explain male behaviors. Women have been ignored in much of the history of criminology, leading one criminologist to comment that their inclusion could result in discarding theories because of their inapplicability to women (Reckless 1967). During the late 1960s, the feminist critique of criminology began emerging to challenge the omission of women (Heidensohn 1969). But even today, says Chesney-Lind (2006), the lack of attention to gender continues, and therefore, the issue of gender gap has yet to be fully examined. This is even more so outside the United States.

One untested but frequently suggested explanation for why females are less inclined to cheat is that a sense of responsibility for the maintenance of social relationships stressed in female socialization encourages moral reasoning governed by the "ethic of care" (Gilligan 1982), which promotes a stronger bonding to the conventional order.

\section{Social Bond and Academic Cheating}

We lack adequate empirical evidence of a link between social bond and academic cheating. Thus, providing such evidence is a major objective of the present research. The four elements of social bond identified by Hirschi (1969) are attachment, commitment, involvement, and beliefs. First, individuals who are attached to conventional others are less inclined to commit deviance for fear of hurting the feeling of those to whom they are attached and/or jeopardizing their relationships with them. Second, those who have made investments in conventional goals, such as education and preparation for labor force participation, are less likely to commit rule violations because they have more to lose by taking the risk of getting caught and being punished for such behavior. Third, individuals who have made investment of time in conventional activities are less prone to deviance because the time spent in such activities reduces time available for deviance and exposure to opportunities for such behavior. Finally, individuals who hold the belief in the moral legitimacy of the societal rule are less likely to transgress because of the view that the rule is binding on their own behavior and has legitimacy in prohibiting their pursuit of self-interest through acts of force and fraud.

Among the limited number of studies that have applied theories of deviance as explanations of academic cheating (e.g., Bolin 2004; Cochran et al. 1999), only a few of them have focused on Hirschi's (1969) social control theory. Thus, it has not been determined whether the theory itself is effective 
in accounting for gender differences in levels of cheating, although two studies by Michaels and Miethe (1989) and Vowell and Chen (2004) attempt to address this issue. Both have serious shortcomings, however.

Michaels and Miethe (1989) provide evidence which appears inconsistent with the hypothesis that students with stronger social bonds to a conventional society are less inclined to cheat. Operationalizing an attachment component as the proportion of friends who had cheated "at least occasionally" (1989: 875), the authors found that those respondents reporting that their friends had cheated were more likely to engage in homework cheating and overall cheating. This operationalization, however, is a questionable proxy for attachment because it refers to the attachment that respondents have to their "deviant" friends (i.e., cheaters), whereas Hirschi (1969) stresses the attachment that the youth have to their "conventional" friends. Attachment to peers, according to Hirschi, should have inverse effects on cheating.

More recently, Vowell and Chen (2004) used a similar measure of the dependent variable - respondents' assessments of how many times they had copied someone's homework and test and allowed someone to copy their homework and the answers from their tests. In this study, measures of attachment to family and college were included and attachment to school was found to decrease the likelihood of cheating. Moreover, measures of full-time student status, frequency of religious service attendance, and campus club/organization membership were included which represent both commitment and involvement. Arguing for a parallel between these two elements, the authors found that the effects of these elements on cheating were negative in direction, as expected from the theory. This operationalization, however, is problematic because although Hirschi (1969) discusses the possibility of interaction between the two elements, commitment and involvement, in his formulation, serve essentially as separate constraints to deviant behavior. Thus, combining these two in a single variable may suppress the effect of each element.

Two specific issues relevant to the present study have surfaced in this body of research. First, in examining the causal link among gender, social bond, and academic cheating, including all four elements of social bond is essential. Furthermore, for youth, relevant attachments are those to parents, peers, and school. Social control theory is more elaborative, however, detailing that the three sub-components of attachment to parents-affectional identification, intimate communication, and supervision-reduce the likelihood of deviant behavior. Yet, to the best of our knowledge, direct tests of the theory, including the two notable studies above, have failed to include measures of all the key variables from the theory.

Second, the target sample in tests of the applicability of social control theory to academic cheating has largely been adolescents in the United States 
(for recent exceptions, see Birchard 2006; Kobayashi 2011). The theory, like many other theories of deviance, has typically been based on American samples and American behaviors, leading Junger and Marshall (1997: 80) to comment that "many of today's criminological theories have been formulated by American scholars and were either explicitly (e.g., Merton 1976; Quinney 1980) or implicitly (Shaw and McKay 1942) designed to apply to American society." During the last few decades, several tests of the theory have been conducted in Western countries other than the U.S. (Junger and Marshall 1997), and a few have been conducted with data from Asian countries, including South Korea (Hwang and Akers 2006), Japan (Fukushima, Sharp, and Kobayashi 2009), and China (Wang et al. 2002). However, none of these studies have tested the theory to account for gender differences in levels of academic cheating.

\section{Gender and Social Bond}

During the past forty years, much effort with mixed results has been devoted to examining whether Hirschi's (1969) social control theory, which was derived out of research on male samples, is equally effective in explaining female deviance (e.g., Chesney-Lind and Shelden 2004; Mears, Ploeger, and Warr 1998; see also Chapple, McQuillan, and Berdahl 2005 for a review). However, the issue of gender gap has yet to be fully examined. Consequently, little has been revealed about whether females are more strongly bonded to a conventional society through attachment, commitment, involvement, and belief.

Meanwhile, the literature utilizing social control theory to examine gender differences in deviance usually refers to the argument that males and females have different socialization experiences (e.g., Friedman and Rosenbaum 1988; Smith and Paternoster 1987). Male social development is predicated on a sense of individuality, or an "ethic of justice", whereas female socialization stresses a sense of responsibility for the maintenance of social relationships, or an "ethic of care" (Gilligan 1982).

This gendered socialization is illustrated by Tannen (1992) as she reveals that boys and girls engage more in "report talk" (transferring information) and "rapport talk" (exchanging feelings to establish relationships), respectively. van Rossum (1998) also finds that boys tend to choose games allowing them to compete and excel, whereas girls tend to do so for the fun of being together and for not being left out. Consequently, such gendered socialization results in gender differences in bonds to the conventional order, with such bonding being stronger and more important for females than for males. Specifically, the emphasis on the importance of maintaining relationships with others in female socialization should promote stronger attachments to conventional 
others, a greater commitment to conformity (resulting in greater potential costs from deviance), greater involvement in conventional activities, and a stronger sense that the societal rules are morally binding on one's own behavior.

However, evidence for this argument has not been consistently favorable. Jensen and Eve (1976) used the data collected from adolescents, part of which were reported by Hirschi (1969) in Causes of Delinquency, to examine the four elements of social bond as the intervening variables linking gender to delinquency. Among white and black respondents, 48 and 38 percent of the effects of gender on delinquency, respectively, are because of gender differences in attachment, commitment, involvement, and belief. But even simple comparisons of the male and female samples for these theoretical variables are not reported. Canter (1982) then investigated the gender differences in the four elements of social bond which she calls "family correlates" and reported evidence which suggests that females are more strongly attached to conventional others (i.e., family), make more investments in conventional family goals, and hold a stronger belief in the legitimacy of the social order. Smith and Paternoster (1987) also observe that females score higher on parental supervision, attachment to peers, and involvement in conventional activities such as organized school events or house chores. But such differences are not apparent on measures of affectional identification with parents, commitment to education, and moral beliefs.

In summary, we find rather inconsistent evidence that females are more strongly bonded to a conventional society through attachment, commitment, involvement, and beliefs. This is in part because, as Kempf (1993) suggests, measures of social bonds that have been tested are not comparable across studies and, as noted earlier, often times they do not include a complete set of social bonds. Particularly, close inspections of this literature have led to the suggestion that these mixed results may be due, in part, to the different operationalizations of parental attachment.

Our data include measures of all four elements of Hirschi's (1969) social bonds and all three dimensions of attachment (i.e., parents, peers, and school) and measures for all three components of attachment to parents (i.e., affectional identification, intimacy of communication, and supervision). We also try as much as possible to use measures identical to those used by Hirschi's (1969) original research so that we can fully assess the role of social bond in connecting gender to cheating.

\section{Gender Differences in Socialization and Masculinity}

Research on gender differences in levels of academic cheating reveals an interesting insight into a fundamental difference between Japanese and Western cultures. In traditional Japanese culture, child socialization differs 
more between boys and girls. In fact, there is a striking polarity of malefemale references as boys and girls are being socialized to conform to the notion of division of roles based on gender: the informal "ore" ("I") and more formal "boku" are used exclusively by boys, while the standard formal "watashi" ("I"), the only pronoun usually available for females, is used by girls. Indeed, the gender gap in socialization, which is accelerated by what Hofstede (1980) calls "high masculinity", is a benchmark characteristic of Japanese culture.

Hofstede (1991:82) notes that masculinity is "the only dimension to emerge in his study that involved male and female differences across cultures." Masculinity cultures emphasize differentiated gender roles. In high masculinity cultures, Hofstede and Hofstede (2004:117) argue, males are socialized to be "assertive, competitive, and tough" in order to succeed in the labor force. Females, on the other hand, are encouraged "to be more concerned with taking care of the home, of the children, and of people in general" in preparation for their future adult roles in the family.

Many scholars have noted the higher "masculinity" orientation of Japanese culture compared with U.S. culture. In their seminal study of IBM subsidiaries around the world, Hofstede and Hofstede (2004) found Japan and the United States to score 95 (ranked the 2nd of 74 countries and regions) and 62 (ranked the 19th), respectively, on the masculinity index (50 is the average score). Thus, Japanese, more so than Americans, tend to be oriented toward masculinity as a cultural value. These findings have been replicated and confirmed by others. Human Development Report (2009), for example, reveals that Japan, in comparison with the U.S., has greater gender disparity in earned income and in opportunities in selected areas such as the share of female legislators and senior officials.

Several studies also report that Japanese socialize boys and girls in more distinct ways than do Americans. A survey of adult females revealed that Japanese are more inclined than their American counterparts to encourage their children to conform with the notion of femininity and masculinity: 63 percent of the Japanese was in favor of the sex-differentiated socialization, while the comparable figure for the Americans was 31 percent (Office of Prime Minister 1982). Dennis et al. (2007) also observed that Japanese mothers are more likely than their American counterparts to instill a sense of autonomy into boys and a sense of relatedness into girls. Consequently, in Japan, boys and girls develop a penchant for a sense of independence and interdependence, respectively, as they are being socialized for gender distinctive roles that places a premium on masculinity.

We suggest that the greater "masculinity" orientation of Japanese culture has implications for the gender differences in levels of academic cheating. 
Recall that in Hirschi's (1969) social control theory, deviance occurs when the individual's bond to conventional society is weak or broken. But in Japanese culture, with its clearer distinction of gender roles, the gender socialization appears to be more pronounced. Boys are more strongly encouraged to compete and excel, whereas girls are socialized to strive for a better relationships with others. Consequently, we argue that masculinity cultures like Japan produce women who are more interconnected through a web of social obligations, and therefore, women in such cultures are tied more strongly to a conventional society. If so, then perhaps the gender difference in the strength of social bond is more apparent and wider, with the gender difference in levels of cheating, in consequence, being greater in Japan.

\section{Hypotheses}

The arguments above lead to the following three hypotheses:

H1: Japanese female college students score lower than males on selfreported academic cheating.

H2: Japanese female college students score higher than males on all four elements of the social bond.

H3: The lower level of self-reported academic cheating among Japanese female college students than males is explained by their stronger social bond.

\section{Sample}

Data were collected as part of a survey of students conducted in a public university in Japan, in spring 2003. With the data only from Japan, "cross-cultural" comparisons are thus not possible. The university has an enrollment of approximately 16,500 and is within a metropolitan area of about 2.2 million inhabitants that contains the capital city of the prefecture. The respondents were registered in the sophomore level courses in a variety of majors. ${ }^{1}$ These included all nine undergraduate majors at the university, such as literature, economics, science, engineering, and education. Because most studies of academic cheating consist of students of one academic discipline (e.g., LanzaKaduce and Klug 1986; Pratt and McLaughlin 1989), we argue that the current study has more generalizability than such previous studies.

The target, given resources available, was a usable sample of about 450 students in lower-division courses in the university. With this target size in mind, eight classrooms were selected and a total of 442 Japanese questionnaires were distributed to the students who agreed to participate in the survey, so the response rate was 100 percent. The questionnaire cover letter clearly 
stated that participation in the study was voluntary and that both the anonymity of the respondents and the confidentiality of their responses were guaranteed. The sample does not differ significantly from the university's undergraduate population in percent male $(71 \%$ in the sample and the population) or percent non-Japanese ( $2 \%$ in the sample and the population). ${ }^{2}$ Nine non-Japanese were eliminated, resulting in an number of 433 for the analysis.

\section{Variables and Measures}

\section{Academic Cheating}

The measure of respondent's Academic Cheating includes six types of dishonesty, as shown in Table 1 (reported in abbreviated form). Respondents were asked to answer the question, "How often have you engaged in the following behaviors in the past year?", using a five-point scale ranging from "never" (coded 0) to "almost always" (coded 4). Because the distribution is skewed for all six items (i.e., means were toward the low end of the 0-4 response range), each item is dichotomized based on those who "never" engaged in the behavior in the past year (coded 0) and those who did (coded 1). The eigenvalues indicated a single-factor model. Reliability analysis revealed a maximum alpha of .67 with all items in the scale. The academic cheating scale in the analysis that follows is a sum of $z$-score transformations

Table 1

Descriptive Statistics for Academic Cheating Scale $(n=433)$

Factor

Item*

Mean SD loadings $\dagger$

Copied or looked at answers during a quiz or test

$\begin{array}{rrr}.464 \quad .499 & .746\end{array}$

Bought a paper over the Internet and turned it in

$\begin{array}{lll}.365 \quad .482 & .646\end{array}$

Copied someone else's work and turned it in

$\begin{array}{lll}.621 & .486 & .655\end{array}$

$\begin{array}{llll}\text { Used cheat notes, etc., when taking an exam } & .344 & .476 & .736\end{array}$

$\begin{array}{llll}\text { Plagiarized a paper for a class } & .478 & .500 & .432\end{array}$

$\begin{array}{lllll}\text { Received an illicit copy of an exam prior to the exam } & .120 & .326 & .417\end{array}$

Notes: *Response options: $0=$ "never"; 1 = "rarely"; "sometimes"; "often"; and "almost always".

$\dagger$ All eigenvalues from principle component analysis: $2.306, .944, .922, .701$, .616 , and .462. 
of the six items coded dichotomously, with a mean of 0 and a standard deviation of 3.67 .

\section{Gender}

In the analysis, gender is the key independent variable, coded 1 for females and 0 for males. The variable Female has a mean of .29 with a standard deviation of .45 .

\section{Control Variables}

In all analyses, we control for age, family structure, and parents' education typically included in tests of theories of deviance. The sample has restricted age distributions because of the population from which it was drawn. The mean age of the sample is 19.37 ( $\mathrm{SD}=.64)$, with 99.1 percent between the ages of 18 and 21 .

Because family structure, in terms of the presence of one adult versus more than one adult at home while growing up, might affect the level of direct control exerted over children and their deviance (Rebellon 2002), we included a measure of family structure as a control variable. The measure Single-Parent Home was created by coding respondents who were raised by one adult as 1 and those who were raised by two or more adults as 0 . This variable has a mean of .05 $(\mathrm{SD}=.21)$, reflecting the low prevalence of non-traditional families in Japan.

The original survey included a question for household income as a measure of parental socio-economic status. However, a high percentage of respondents $(37.5 \%)$ indicated that they did not know and could not even estimate it. Consequently, parents' education, instead of household income, is used as the indicator of parental socio-economic status. We chose to simply distinguish between respondents for whom at least one parent had a bachelor's degree or higher (coded 1) and all other respondents (coded 0). The variable Parents' Education has a mean of $.67(\mathrm{SD}=.47)$.

\section{Social Bond Variables}

The questionnaire contains seven items measuring all three components of attachment to parents, and each of them was presented to the respondents separately for their mother and father: (1) three items for affectional identification, with response options ranging from "not at all like me" (coded 1) to "very much like me" (coded 4)-"I want to be like my mother/father" $($ mean $=1.97 / 2.00, \mathrm{SD}=.93 / .99)$, "I feel extremely close to my mother/father" (mean $=2.76 / 2.35, \mathrm{SD}=.89 / .99)$, and "I get all the affection I want from my mother/father" (mean $=2.42 / 2.24$, SD $=.96 / .99)$; (2) two items for intimacy of communication, the first item answered on scale ranging from "not at all like me" (coded 1) to "very much like me" (coded 4) and the 
second item on a scale ranging from "not at all" (coded 1) to "a great deal" (coded 5) - "I often engage in leisure activities with my mother/father" $($ mean $=2.13 / 1.82, \mathrm{SD}=.94 / .90)$ and "My mother/father is willing to listen when I need to talk about my worries or problems" (mean $=2.32 / 2.85$, $\mathrm{SD}=1.25 / 1.26$ ); and (3) two items for parental supervision, with response options of "never" (coded 0), "sometimes" (coded 1), and "often" (coded 2) - "When I was away from home, my mother/father knew where I was" $($ mean $=1.90 / 1.64, \mathrm{SD}=1.22 / 1.77)$ and "When I was away from home, my mother/father knew whom I was with" (mean $=1.75 / 1.41, \mathrm{SD}=1.27 / 1.89$ ).

Our original intent was to create an overall scale of parental attachment with all the seven items. With this goal, responses were first summed for each of the pairs (i.e., mother and father) of these items to create a separate scale for each of the three components. Principal components analysis indicated a single factor with an alpha of .74 for affectional identification, .54 for intimacy of communication, and .83 for parental supervision. With the goal of parsimony, these three subscales were then subjected to principal components and reliability analyses. The reliability analysis, however, indicated that the creation of this single scale of "parental attachment" could not be justified. Instead the Parental Attachment scale is the sum of the $z$-scores of affectional identification and intimacy of communication with an alpha of .75 ( $S D=1.75$ ), leaving Parental Supervision as a separate variable with an alpha of $.83(\mathrm{SD}=1.85)$.

Attachment to Peers is measured with the following question, with response options of "not at all" (coded 0), "in a few ways" (coded 1), and "in most ways" (coded 2) - "Would you like to be the kind of person your close friends are?" (mean $=.88, \mathrm{SD}=.51$ ). Attachment to School is measured with the following question, with response options ranging from "I disliked school" (coded 1) to "I liked school" (coded 3) - "In general, did you like or dislike high school?" (mean $=2.62, \mathrm{SD}=.61$ ). We chose high school rather than college as the frame of reference because students in the sample were rather early in their college careers and, therefore, might not have solidified views about attachment to college.

Commitment is assessed by the importance respondents place on achieving the following three conventional goals, with response options ranging from "not very important" (coded 1) to "very important" (coded 4) - "getting good grades in college" ( mean $=2.44, \mathrm{SD}=.89)$, "graduating from college" $($ mean $=3.39$, $\mathrm{SD}=.78$ ), and "getting the job I want when I finish my education" (mean $=3.58$, $\mathrm{SD}=.69$ ). The principal components analysis indicates a single factor, with an alpha of .63 for the linear composite of the three items $(\mathrm{SD}=2.28)$.

To measure Involvement in conventional activities, respondents were asked whether they were involved in (and, if so, how many hours per week) seven kinds of activities including: a job, an academic club, a community 
organization, school band or orchestra, organized athletics, class other than school, and others. In the analysis that follows, the measure of involvement is a sum of the hours of participation in these activities for each student, with a mean of $17.22(\mathrm{SD}=12.83)$.

Finally, Belief in the legitimacy of the law is a scale created from four items, each answered on a four-point scale ranging from "strongly agree" (coded 1) to "strongly disagree (coded 4), including some from Hirschi's (1969) original study, such as "It is all right to get around the law if you can get away with it" ( $m e a n=3.23, \mathrm{SD}=.64)$, "To get ahead, you have to do some things that are not right" ( let other people do what they want to do as long as nobody gets hurt even if it is against the law" (mean $=2.84, \mathrm{SD}=.77$ ), and "Most things people call delinquency do not really hurt anyone" (mean $=3.19, \mathrm{SD}=.65$ ). The principal components analysis indicates a single factor, with an alpha of .59 for the linear composite of the $z$-score transformations of the four items $(\mathrm{SD}=2.67)$.

\section{Analysis and Findings}

\section{Partial Correlations}

Table 2 reports partial correlations linked to our hypotheses, with controls for age, single-parent home, and parents' education. Because direction is

\section{Table 2}

Partial Correlations Between Female and Theoretical Variables, $n=433$

(one-tailed tests)

\begin{tabular}{lrr} 
Variable & Partial correlations* & $p$ \\
\hline Academic cheating & -.122 & .006 \\
Attachment to parents & .179 & $<.001$ \\
Parental supervision & .151 & .001 \\
Attachment to school & .052 & .142 \\
Attachment to peers & .107 & .014 \\
Commitment & .148 & .001 \\
Involvement & -.021 & .333 \\
Belief & .149 & .001
\end{tabular}

Note: *Controlling for respondents' age, single-parent home, and parents' education. 
predicted in all hypotheses, one-tailed tests are appropriate, and the conventional .05 level is used for judgments concerning significance.

As expected, there are significant positive correlations between Female and five of the social bond variables. ${ }^{3}$ The correlations range from a low of $.107(p=.014)$ for Attachment to Peers to a high of $.179(p<.001)$ for Attachment to Parents, indicating that the Japanese females are significantly more likely than the males to feel attached to their parents and close friends, be supervised by their parents, have made investments in conventional goals, and hold the belief in the legitimacy of the societal rule. However, while the correlation for Attachment to School $(r=.052, p=.142)$ is in the predicted direction, it not significant. The correlation between Female and Involvement is not significant either; in fact, it is inverse $(r=-.021)$ in sign, contrary to what we have expected. Finally, the correlation between Academic Cheating and Female is $-.122(p=.006)$, consistent with the predicted inverse relationship. ${ }^{3}$

\section{Regression Analysis of Academic Cheating}

Table 3 considers the extent to which the lower level of cheating among females, as observed in Table 2, can be explained by the seven key variables from social control theory treated as intervening variables. It is important to note that the contributions of the gender difference in any one social bond variable to this gender differing cheating level is a function of the magnitude of gender difference in the social bond and the magnitude of the effect of that social bond on commission of cheating. Recent research demonstrates that belief in the legitimacy of the law is a strong constraint to deviant behavior, stronger than the other elements of social bond (e.g., Fukushima, Sharp, and Kobayashi 2009; Kobayashi 2011).

Before estimating direct effects of Female in ordinary least squares (OLS) regressions, we should mention that isolating the independent contributions of the seven social bond variables to the gender difference in the commission of cheating is not a simple task because the theoretical variables are significantly correlated with one another. Certain correlations might be expected from Hirschi's formulation: Those who are attached to conventional others and institutions should also be committed to achievement. The bivariate correlation between Attachment to Parents and Commitment was .175 $(p<.001)$; between Parental Supervision and Commitment, .116 $(p=.008)$, between Attachment to School and Commitment, .131 $(p=.003)$. Hirschi (1969: 30) also contends that "Insofar as the child respects (loves and fears) his parents, and adults in general, he will accept their rules." The correlation between Attachment to Parents and Belief was .204 $(p<.001)$; between Attachment to School and Belief, .170 $(p<.001)$. We examined the 


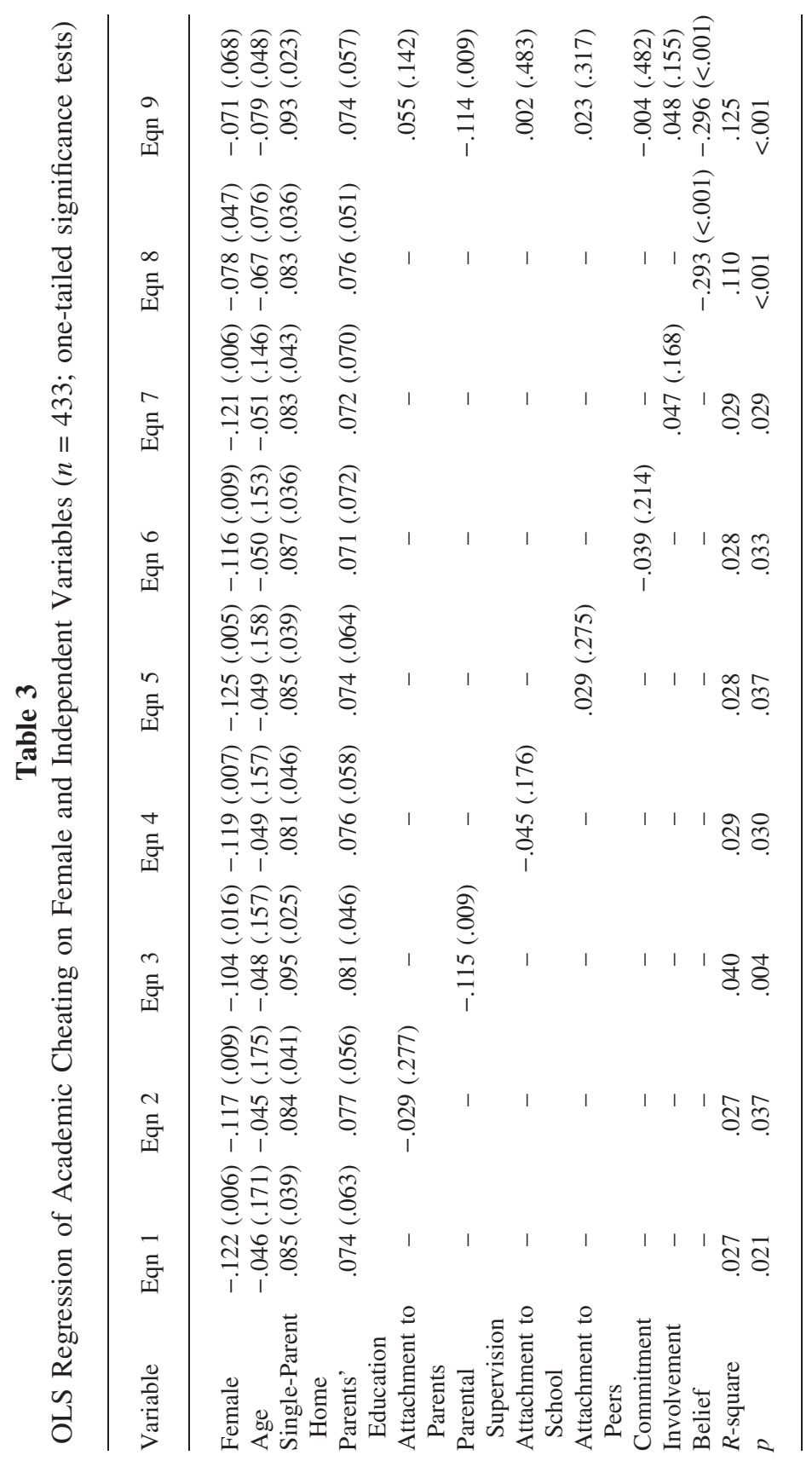


multicollinearity diagnostics from SPSS in the various regressions, but they indicated no harmful multicollinearity problem (Belsley 1982).

Equation 1 reports the standardized effect of Female on Academic Cheating, which is equivalent to the partial correlation in Table 2. The significant inverse effect $(\beta=-.122, p=.006)$ simply indicates that the female respondents are less likely to cheat than the males. Among the control variables, Single-Parent Home has a significant positive effect $(\beta=.085, p=.039)$, with students who have grown up in household with only one adult being more inclined to cheat.

Equations 2-8 add, one at a time, each of the seven theoretical variables to the equation containing Female and the control variables. These equations indicate the extent to which each variable, by itself without controls for the others, account for the inverse effect of Female. This can be judged by comparing the effects of Female in eqns 2-8 to the effect of Female in Equation 1. Clearly, the variable that by itself is most effective in accounting for the inverse effect of Female is Belief. The Beta of -.122 for Female in Equation 1 is reduced by 36 percent to -.078 , although it barely remains significant with the addition of Belief in eqn 8. In the other equations, when the other social bond variables are considered separately, the reduction in the effect of Female is less than in eqn 8. In fact, the effects for Female are not much different from that of -.122 in Equation 1. These comparisons, therefore, suggest that the stronger belief in the legitimacy of societal rules among the females is the primary source of their less inclination toward cheating.

Equation 9 provides additional evidence for this conclusion. When all seven social bond variables are in the equation, the Beta of -.071 for Female is only slightly smaller than that of -.078 from Equation 8, which contains only Belief, although Female is no longer significant at the conventional level $(p=.068)$. Thus, the stronger Attachment to Parents, Parental Supervision, Attachment to Peers, Attachment to School, Commitment, and Involvement among females contribute very little, beyond their stronger Belief, to their less likelihood of academic cheating.

While the gender differences in these theoretical variables appear to contribute little beyond the effect of Belief to the lower cheating level among the females, Parental Supervision $(\beta=-.114)$, along with Belief $(\beta=-.296)$, does have a significant inverse effect on Academic Cheating in eqn 9. In other words, both Parental Supervision and Belief are significant constraints, but the stronger Belief among the females is primarily responsible for their lower tendency toward cheating.

\section{Discussion and Conclusions}

To date, research on academic cheating has typically centered around identifying correlates of such dishonesty. Thus, few attempts have been made 
to address the issue of gender gap, exploring theories of deviance as a potential tool for understanding gender differences in levels of cheating. ${ }^{4}$

In this article, we have argued that a sense of responsibility for the maintenance of social relationships emphasized in female socialization fosters a stronger attachment to conventional others and institutions. While the socialization of boys and girls may be converging in the United States (Buchmann and DiPrete 2006), it appears less so in Japan because of its stronger orientation toward masculinity, having implications for greater gender differences in the strength of attachment. This leads us to look to social control theory as a tool for understanding gender differences in levels of cheating. In the present research, we have operationally defined the theoretical concept of social bond in a manner similar to Hirschi's (1969) original research, and we have presented data from a sample of college students in Japan. We find that social bond defined this way is, in general, stronger for females than for males and academic cheating is less common among the females. Particularly, the stronger belief in the legitimacy of societal rules among the females generates their less likelihood of cheating. Where might this difference then come from?

An obvious answer and area for future research is the gender patterning of socialization. As noted earlier, the socialization of females for maintenance of social relationships produces a stronger belief that the norms of society are morally binding on their own behavior. Furthermore, having being raised in a culture high on masculinity, the Japanese are subject to more gender-distinct socialization during childhood. If our evidence of the social bond as the intervening variables linking gender to cheating withstands more rigorous tests which include a measure(s) of socialization for the maintenance of relationships with others, we could then present a more convincing causal link among gender, social bond, and cheating.

However, our findings also suggest that certain features of social control theory require further consideration as researchers explore such issues.

First, the relative importance of the contributions of each of the four elements of social bond to academic cheating requires further consideration. In Hirschi's (1969) formulation, individual commission of deviance results in part from all four elements of the social bonds. Among the Japanese college students in the present sample, however, attachment to conventional others (i.e., parents, peers, and school), parental supervision, commitment, and involvement, beyond the belief element, did neither reduce the magnitude of the effect of Female nor have significant inverse effects on Academic Cheating, although the parental supervision did have a significant effect. One possibility is that these four elements equally impact more violent and serious forms of deviance, while the belief element affects more strongly less violent and serious forms of deviance such as academic cheating that we have examined. 
Another possibility is that more refined measures of the elements might have generated results more consistent with the theory. In this article, we have tried as much as possible to use measures identical to those used by Hirschi (1969). However, consideration of additional items, such as "Do you care what teachers think of you?", which corresponds to the attachment to school, and "Do you share your future plans with your mother/father?" and "When you don't know why your mother/father makes a rule, will she or he explain the reason?", which represent the intimacy of communication from the child to the parent and communication from the parent to the child, respectively, might increase the explanatory power of social control theory.

Second, our results indicate no gender differences in the strength of attachment to school and involvement in conventional activities. One possible interpretation of these findings, contrasted with our expectations, is that less patriarchal families are becoming more common, as women increasingly enter positions of authority in the work force and as the proportion of female headed households increases (e.g., Grasmick, Blackwell, and Bursik 1993; Hagan, Simpson, and Gillis 1987), leading some Japanese female students, as well as some males, who were raised in less patriarchal families as children to find themselves bonded less to a conventional society. These changes in family structure should produce a convergence between women and men for socialization for the maintenance of social relationships. Therefore, the consequences of this socialization become an important topic for studies of social control theory.

Third, concern with the gender differences in cheating found among the Japanese students directs attention to the issue of cross-cultural generalizability of social control theory. In this preliminary study, we have relied on earlier literature to characterize Japanese as subject to more gender-distinct socialization during childhood and have not measured whether this was true for the respondents in our study. Moreover, we have assumed from previous literature, and hence offered no empirical evidence, that the Japanese respondents are, in fact, oriented more toward masculinity. ${ }^{5}$ As the focus of the theory expands to emphasize not only gender differences but also magnitudes of such differences across cultures in cheating, the manner in which and the extent to which differences in socialization between boys and girls is distinct across cultures becomes a central concern, much as it might be in the current study of the age of our respondents (i.e., Japanese college students). Finally, differences in educational systems across cultures would be helpful in stimulating more ideas on this subject of academic cheating in Japanese universities. What matters in Japan is getting into a good university, not so much being a good student when one gets into a good university. Kerbo and McKinstry (1998) observe that in Japan, unlike the United States, opportunities for success are 
channeled into an extremely tapered selection process called "juken sensou" (fiercely competitive exams) with no alternative paths or second chances. Adult outcomes (i.e., successful career) are determined during a condensed period of a couple of days in spring when a person 18 years of age sits for the examination for entrance into the university system. Future research should refine our approach and consider culture as it interacts with its educational system to shape students' decisions to cheat or not to cheat academically.

In conclusion, we want to emphasize that ours is not the definitive study of the applicability of Hirschi's (1969) social control theory to gender differences in academic cheating in Japan. First, our sample of college students is a convenience sample and therefore, should not be considered to be fully representative of the university population, nor of college student populations in the country. Accordingly, the lack of variation on age, education, parental socioeconomic status, and family structure may have restricted our ability to generalize our findings. Future research should consider whether our arguments about gender differences and our findings apply to a broader range of student population in Japan. Second, as noted earlier, a better test of the applicability of social control theory to the relationship between gender and cheating, as it applies to the Japanese culture, would involve examining whether the gender patterning of socialization is related to the gender differences in the strength of social bonds and then in the commission of cheating. Third, our research focuses on social bond and includes measures of important variables from the theory. But entering additional variables from social control and other theories of deviance may capture sources of variances that is not explained in this study, and could enable better understanding of gender differences as well as similarities in cheating across cultures.

\section{ENDNOTES}

*Research reported here was supported by the Grants-in-Aid for Scientific Research from the Japanese Ministry of Education, Culture, Sports, Science and Technology. We are most grateful to Harold G. Grasmick for his comments on earlier versions of the manuscript. We are also thankful to anonymous reviewers of this journal for their insightful comments and critiques. Please direct all correspondence to: Emiko Kobayashi, Foreign Language Institute, Kanazawa University, Kanazawa, Ishikawa 920-1192, Japan; e-mail: ekobaya@staff.kanazawa-u.ac.jp

${ }^{1}$ Although college undergraduate students were chosen as respondents, we realize that lower grades or those who decide not to enroll in college are excluded from our research design and might be more (or less) inclined to engage in academic cheating than those who attend college.

${ }^{2}$ In general, Japanese national universities are overwhelmingly male. According to the figures released by the Japanese Bureau of Statistics (Statistics Bureau 2003), 66 percent of all students enrolled in all national universities are males. 
${ }^{3} \mathrm{We}$ also performed the analysis reported in Table 2 with controls for the social bond variables. However, inclusion of the controls did not alter the conclusions concerning the direction of r's and its significance.

${ }^{4}$ Another important issue identified by the feminist approach is the gender generalizability (Daly and Chesney-Lind 1988) which concerns whether theories developed to explain male deviance are equally effective in explaining female deviance. Analyses were then performed separately for males and females to compare the effects of the social bond variables on self-reported cheating. The $z$-tests recommended by Paternoster et al. (1998) reveal that for any one of the theoretical variables, the difference in the $b$ (unstandardized coefficient) for the males and the females is not significant, thus negating the possibility that the social bond variables may affect the propensity for academic cheating differently for males and females.

${ }^{5}$ The concept of "masculinity" also indicates more pressure on males to succeed professionally and economically, thus putting more pressure on them to cheat. Thus, future research needs to explore how the pressure on males and females for this success differs across cultures and these are related to gender differences in cheating.

\section{REFERENCES}

Belsley, David A. 1982. "Assessing the Presence of Harmful Collinearity and Other Forms of Weak Data through a Test for Single-to-Noise." Journal of Econometrics 20:211-53.

Birchard, Karen. 2006. "Cheating is Rampant at Canadian Colleges." Chronicle of Higher Education 53:A53.

Bolin, Aaron U. 2004. "Self-Control, Perceived Opportunity, and Attitudes as Predictors of Academic Dishonesty." The Journal of Psychology 138:101-14.

Bowers, William J. 1964. Student Dishonesty and its Control in College. New York: Bureau of Applied Social Research, Columbia University.

Buchmann, Claudia and Thomas A. DiPrete. 2006. "The Growing Female Advantage in College Completion: The Role of Family Background and Academic Achievement." American Sociological Review 71:515-41.

Canter, Rachelle J. 1982. "Family Correlates of Male and Female Delinquency." Criminology 20:149-67.

Center for Academic Integrity. 2006. "CAI Research." Durham, NC: The Center for Academic Integrity. Retrieved April 27, 2006. http://www.academicintegrity.org/cai_research.asp.

Chapple, Constance L., Julia A. McQuillan, and Terceira A. Berdahl. 2005. "Gender, Social Bonds, and Delinquency: A Comparison of Boys' and Girls' Models.” Social Science Research 34:357-83.

Chesney-Lind, Meda. 2006. "Patriarchy, Crime, and Justice: Feminist Criminology in an Era of Backlash.” Feminist Criminology 1:6-26.

Chesney-Lind, Meda and, Randall G. Shelden. 2004. Girls, Delinquency, and Juvenile Justice, 3rd ed. Belmont, CA: Thompson/Wadsworth.

Cochran, John K., Mitchell B. Chamlin, Peter B. Wood, and Christine S. Sellers. 1999. "Shame, Embarrassment, and Formal Sanction Threats: Extending the Deterrence/Rational Choice Model to Academic Dishonesty.” Sociological Inquiry 69:91-105.

Crown, Deborah F. and M. Shane Spiller. 1998. "Learning from the Literature on Collegiate Cheating: A Review of Empirical Research." Journal of Business Ethics 17:683-700. 
Daly, Kathleen and Meda Chesney-Lind. 1988. "Feminism and Criminology." Justice Quarterly 5:497-535.

Dennis, Tracy A., Makram Talih, Pamela M. Cole, Carolyn Zahn-Waxller, and Ichiro Mizuta. 2007. "The Socialization of Autonomy and Relatedness: Sequential Verbal Exchanges in Japanese and U.S. Mother-Preschooler Dyads." Journal of Cross-Cultural Psychology 38:729-49.

Diekhoff, George M., Emily E. LaBeff, Kohei Shinohara, and Hajime Yasukawa. 1999. "College Cheating in Japan and the United States." Research in Higher Education 40:343-53.

Friedman, Jennifer and Dennis P. Rosenbaum. 1988. "Social Control Theory: The Salience of Components of by Age, Gender, and Type of Crime." Journal of Quantitative Criminology 4:363-81.

Fukushima, Miyuki, Susan F. Sharp, and Emiko Kobayashi. 2009. "Bond to Society, Collectivism, and Conformity: A Comparative Study of Japanese and American College Students." Deviant Behavior 30:434-66.

Gilligan, Carol. 1982. In a Different Voice: Psychological Theory and Women's Development. Cambridge, MA: Harvard University Press.

Gottfredson, Michael and Travis Hirschi. 1990. A General Theory of Crime. Stanford: Stanford University Press.

Grasmick, Harold G., Brenda S. Blackwell, and Robert J. Bursik Jr. 1993. "Changes in the Sex Patterning of Perceived Threats of Sanctions." Law and Society Review 27:679-705.

Grimes, Paul W. 2004. "Dishonesty in Academics and Business: A Cross-Cultural Evaluation of Student Attitudes." Journal of Business Ethics 49:273-91.

Hagan, John, John Simpson, and A. R. Gillis. 1987. "Class in the Household: A Power-Control Theory of Delinquency." American Journal of Sociology 92:788-816.

Heidensohn, Frances. 1969. "The Deviance of Women: A Critique and an Enquiry." British Journal of Sociology 19:160-75.

Hirschi, Travis. 1969. Causes of Delinquency. Berkley, CA: University of California.

Hofstede, Geert. 1980. Culture's Consequences: International Differences in Work-Related Values. Beverly Hills, CA: Sage Publications. -1991. Cultures and Organizations: Software of the Mind. London: McGraw-Hill.

Hofstede, Geert and Gert J. Hofstede. 2004. Cultures and Organizations: Software of the Mind. London: McGraw-Hill.

Human Development Report. 2009. Overcoming Barriers: Human Mobility and Development. UNDP. Retrieved June 11, 2010. http://hdr.undp.org/en/media/HDR_2009_EN_Complete.pdf.

Hwang, Sunghyun and Ronald L. Akers. 2006. "Parental and Peer Influences on Adolescent Drug Use in Korea." Asian Journal of Criminology 1:59-69.

Jensen, Gary J. and Raymond Eve. 1976. "Sex Differences in Delinquency: An Examination of Popular Sociological Explanations.” Criminology 13:427-48.

Junger, Marianne and Ineke Haen Marshall. 1997. "The Interethnic Generalizability of Social Control Theory: An Empirical Test." Journal of Research in Crime and Delinquency 34:79112.

Kempf, Kimberly. 1993. "The Empirical Status of Hirschi's Social Control Theory.” Pp. 143-85 in New Directions in Criminology, (Vol. 4): Advances in Criminological Theory, edited by F. Adler, W. S. Laufer. New Brunswick, NJ: Transaction Publishers.

Kerbo, Harold R. and John A. McKinstry. 1998. Modern Japan: A Volume in the Comparative Socities Series. New York: McGraw Hill.

Kobayashi, Emiko. 2011. "Social Bonds and Academic Cheating: An Application of Hirschi's Social Control Theory." Studies of Language and Culture 15:159-81. 
Lanza-Kaduce, Lonn and Mary Klug. 1986. "Learning to Cheat: The Interaction of MoralDevelopment and Social Learning Theories." Deviant Behavior 7:243-59.

Lin, Chun-Hua S. and Ling-Yu Melody Wen. 2007. "Academic Dishonesty in Higher Education: A Nationwide Study in Taiwan." Higher Education 54:85-97.

McCabe, Donald L., Linda K. Trevino, and Kenneth D. Butterfield. 2001. "Cheating in Academic Institutions: A Decade of Research." Ethics and Behavior 11:219-32.

Mears, Daniel P., Matthew Ploeger, and Mark Warr. 1998. "Explaining the Gender Gap in Delinquency: Peer Influence and Moral Evaluations of Behavior." Journal of Research in Crime and Delinquency 35:251-66.

Merton, Robert K. 1976. Social Theory and Social Structure. New York, NY: McMillan.

Michaels, James W. and Terance D. Miethe. 1989. "Applying Theories of Deviance to Academic Cheating." Social Science Quarterly 70:870-85.

MSNBC.com. 2005. "Charges of Fake Research Hit New High: Doctors Accused of Making Up Data in Medical Studies." The Associate Press, July 10, 2005 (updated). Retrieved April 28, 2006. http://www.msnbc.msn.com/id/8474936/from/ET/.

Office of Prime Minister. 1982. Fujin Mondai ni Kansuru Kokusai Hikaku Chosa [A Comparative International Survey on Women's Issues]. Tokyo, Japan: Sorifu.

Paternoster, Raymond, Robert Brame, Paul Mazerolle, and Alex Piquero. 1998. "Using the Correct Statistical Test for the Equality of Regression Coefficients." Criminology 36:859-66.

Pratt, Cornelius and Gerald W. McLaughlin. 1989. "An Analysis of Predictors of College Students' Ethical Inclinations." Research in Higher Education 30:195-219.

Quinney, Richard. 1980. Class, State, and Crime, 2nd ed. New York: Longman.

Rebellon, Cesar. J. 2002. "Reconsidering the Broken Homes/Delinquency Relationship and Exploring Its Mediating Mechanism(s)." Criminology 40:103-36.

Reckless, Walter C. 1967. The Crime Problem. New York, NY: Appleton-Century-Crofts.

Shaw, Clifford R. and Henry D. McKay. 1942. Juvenile Delinquency in Urban Areas. Chicago, IL: University of Chicago Press.

Sims, Randi I. 1993. "The Relationship Between Academic Dishonesty and Unethical Business Practices." Journal of Education for Business 68:207-11.

Singhal, Avinash C. 1982. "Factors in Students' Dishonesty." Psychological Reports 51:775-80.

Smith, Douglas and Raymond Paternoster. 1987. "The Gender Gap in Theories of Deviance: Issues and Evidence." Journal of Research on Crime and Delinquency 24:140-72.

Statistics Bureau. 2003. "Number of Students at Japanese National Universities." Tokyo, Japan: The Ministry of Education, Culture, Sports, Science and Technology. Retrieved August 25, 2006. http://www.mext.go.jp/b_menu/toukei/002/002b/koumoku.html.

Tannen, Deborah. 1992. You Just Don't Understand: Women and Men in Conversation. London: Virago Press.

Tibbetts, Stephen G. 1997. "Gender Differences in Students' Rational Decisions to Cheat." Deviant Behavior 18:393-414.

. 1999. "Differences Between Women and Men Regarding Decisions to Commit Test Cheating." Research in Higher Education 40:323-42.

Tittle, Charles R. and Raymond Paternoster. 2000. Social Deviance and Crime: An Organizational and Theoretical Approach. Los Angeles, CA: Roxbury.

van Rossum, Jacques H. A. 1998. "Why Children Play: American versus Dutch Boys and Girls." Pp. 130-38 in Masculinity and Femininity: The Taboo Dimension of National Cultures, edited by G. Hofstede. Thousand Oaks, CA: Sage.

Vowell, Paul R. and Jieming Chen. 2004. "Predicting Academic Misconduct: A Comparative Test of Four Sociological Explanations." Sociological Inquiry 74:226-49. 
Wang, Gabe T., Hengrui Qiao, Schaowei Hong, and Jie Zhang. 2002. "Adolescent Social Bond, Self-Control, and Deviant Behavior in China." International Journal of Contemporary Sociology 39:52-68.

Ward, David A. and Wendy L. Beck. 1990. "Gender and Dishonesty." Journal of Social Psychology 130:333-39.

Whitley, Bernard E. 2001. "Gender Differences in Affective Responses to Having Cheated: The Mediating Role of Attitudes." Ethics and Behavior 11:249-59.

Whitley, Bernard E., Amanda B. Nelson, and Curtis J. Jones. 1999. "Gender Differences in Cheating Attitudes and Classroom Cheating Behavior: A Meta-Analysis." Sex Roles 41:65780.

Yoshida, Hiroshi and Takashi Nakagawa. 1971. "Kitsuento Kanningunitaisuru Koukouseino Taido [Attitudes of High School Students toward Smoking and Cheating]." Toyama Daigaku Kyouiku Gakubu Kiyou 18:177-96. 